\title{
VARIEDADES
}

\section{ṬĀLŪT Y EL JUDÍO. ANÁLISIS DE LA EVOLUCIÓN HISTORIOGRÁFICA DE UN RELATO}

\author{
ȚĀLŪT AND THE JEW. ANALYSIS OF THE \\ HISTORIOGRAPHICAL EVOLUTION OF AN ACCOUNT
}

Luis Molina

Escuela de Estudios Árabes-CSIC, Granada

\begin{abstract}
Análisis historiográfico del relato de las vicisitudes del alfaquí TTālūt, elaborado por Ibn al-Qūtiyya y reproducido por numerosas fuentes andalusíes y orientales. De dicho análisis se desprende que la supuesta versión amplia de la crónica de Ibn al-Qūṭiyya nunca existió y que la coincidencia entre varias obras en presentar una versión extensa del relato es debida a su común dependencia de un subarquetipo que amplificó retóricamente el texto original de Ibn alQūtiyya.
\end{abstract}

Palabras clave: Historiografía árabe; Al-Andalus; Ibn al-Qūṭiyya; Ecdótica.
The present paper deals with the account of the faqīh Ṭālūt's vicissitudes, which originated in Ibn al-Qūtiyya's work and was reproduced by several Andalusi and Eastern authors. From the historiographical analysis of that account we can conclude that the fact that some of these authors concur on reproducing a large version is due to their derivation from a common subarchetype, which was responsible for the rhetorical amplification of Ibn al-Qūtiyya's original text. Therefore, the existence of a large version of Ibn al-Qūtịyya's chronicle must be ruled out.

Key words: Arabic Historiography; Al-Andalus; Ibn al-Qūtiyya; Textual criticism.

Son muy numerosas las citas que los cronistas árabes hacen de la obra histórica de Ibn al-Qūtiyya (m. 367/977), pero, al mismo tiempo, no son infrecuentes las ocasiones en las que esas citas se hallan textualmente muy alejadas de la versión conservada en el unicum de París de su Ta'rïj Iftitāh al-Andalus (IQ). Esas divergencias son de tal entidad que no pueden ser explicadas únicamente por las modificaciones normales que sufre un texto en su proceso de transmisión. Tales diferencias han sido atribuidas generalmente a una supuesta condición de borrador provisional de la versión recogida en el ma- 
nuscrito de París, de modo que la versión definitiva sería la seguida en las citas de los historiadores posteriores, que reflejan un texto más amplio y estilísticamente mejorado. El hecho de que en no pocas ocasiones los textos de estos autores coincidiesen entre sí al alejarse de IQ abonaba esa suposición ${ }^{1}$.

Pero algunos indicios impedían aceptar sin objeciones tal hipótesis o, al menos, alguno de sus elementos constitutivos. En efecto, parecía difícil admitir que un modesto borrador de trabajo - o unos apuntes tomados a vuela pluma por algún alumno- hubiese sobrevivido hasta acabar registrado en un manuscrito del siglo $\mathrm{XV}^{2}$, mientras que el texto definitivo de la crónica se perdía sin dejar rastro. Del mismo modo, el que un historiador andalusí un siglo posterior a Ibn al-Qūṭiyya, Aḥmad Ibn Ab̄i l-Fayyāḍ (375459/986-1066) utilizase ese supuesto borrador para elaborar su crónica nos demuestra que en el siglo XI esa versión se hallaba en circulación ${ }^{3}$.

${ }^{1}$ La existencia de varias versiones de la obra de Ibn al-Qūtiyya, idea propuesta ya por Dozy en su edición de al-Bayān al-mugrib (Leiden, 1848-52, 28-30), ha venido siendo aceptada de forma casi unánime; sólo M. Fierro se ha desmarcado de esa explicación en "La obra histórica de Ibn al-Qūṭiyya" (Al-Qanțara, 10 (1989), 485-512, donde se puede hallar un clarificador resumen de la cuestión), aunque sigue considerando que el texto conservado en el manuscrito de París es «la recensión hecha por uno de los discípulos de Ibn al-Qūtiyya a partir del material escuchado de boca de su maestro». Esta cuestión, la de la autoría exacta del Iftitāh (es decir, producto salido de la pluma de Ibn al-Qūtiyya o recopilación de sus transmisiones orales) no afecta para nada a nuestro planteamiento, por lo que no nos hemos de detener en ella. En el más reciente trabajo publicado sobre la figura y la obra de Ibn al-Qūtịya (James, D., Early Islamic Spain. The History of Ibn al-Qütīya, Londres-Nueva York, 2009), el autor concluye que, probablemente, existieron varias versiones del texto en circulación a partir de mediados del siglo IV/X, pero que ninguna de ellas era la definitiva (p. 19) e incluso llega a proponer que la versión representada por el manuscrito de París es un resumen elaborado después de que Ibn Hayyān redactara su Muqtabis (p. 18).

2 James (Early Islamic Spain, 2) distingue tres tipos de filigrana en el papel del manuscrito. Para el primero de ellos encuentra en los catálogos de filigranas ejemplos similares fechados entre 1391 y 1469; para el segundo, entre 1412 y 1444; para el tercero, sólo un caso, de 1443. A falta de mayores precisiones, parece que el manuscrito pudo ser elaborado a mediados del siglo XV.

3 Álvarez de Morales, C. ("Aproximación a la figura de Ibn Abī l-Fayyāẹ y su obra histórica", Cuadernos de Historia del Islam, 9 (1978-9), 29-127), señala los paralelismos entre los textos atribuidos a Ibn Abī l-Fayyād y el Iftitâh , al tiempo que remarca la cita explícita que hace en una ocasión de Ibn al-Qūṭiyya (p. 37, n. 38). C. Sánchez Albornoz aceptaba que Ibn Abī l-Fayyāọ había utilizado la obra de Ibn al-Qūtiyya, mientras que Fierro cree que las semejanzas entre ellas son debidas a que utilizan una fuente común (Fierro, "La obra histórica", 490).

Al-Qantara XXXII 2, julio-diciembre 2011, pp. 533-557 ISSN 0211-3589 
Es cierto que estos dos indicios no pueden ser considerados concluyentes, pues hemos de reconocer que la preservación de ese manuscrito puede ser una circunstancia debida al azar, mientras que el testimonio de Ibn Abī l-Fayyāḍ hay que aceptarlo con muchas cautelas, dado que sólo conocemos su obra a través de citas de otros autores y de un fragmento muy breve cuya atribución a Ibn Abī 1-Fayyāọ no está exenta de dudas.

No obstante, estos argumentos en contra de la existencia de dos versiones del Iftitāh de Ibn al-Qūtiyya no deben ser arrinconados sin más consideraciones. La duda razonable que suscitan ha de llevarnos a ahondar más en la cuestión con la finalidad de hallar pruebas que descarten o confirmen esta hipótesis.

Para ello hemos elegido un relato del Iftitāh de Ibn al-Qūtiyya en que se dan una serie de circunstancias propicias para el objetivo que nos interesa: el texto es reproducido en el Muqtabis de Ibn Hayyān - piedra angular de toda la historiografía sobre al-Andalus omeya-, un número importante de autores de muy diversas épocas lo incorporan a sus obras, incluye una muestra apreciable de discurso referido - pasajes en las que los historiadores suelen conservar con más fidelidad el texto de sus fuentes-, y, lo más importante, es en buena medida una historia de tinte biográfico, lo que ha dado pie a que sea recogida en los diccionarios biográficos, obras en las que se atenúa considerablemente la implacable dictadura hayyāní que modela de forma castrantemente homogeneizadora todo el género cronístico. Ya en un trabajo reciente tuvimos ocasión de demostrar la productividad del recurso a las obras biográficas para estudios historiográficos ${ }^{4}$.

\section{La Historia del alfaquí Ṭālūt}

Al personaje central de esta historia, Țālūt b. 'Abd al-Ŷabbār alMa āfirī, se le atribuye el haber sido discípulo de Mālik b. Anas; a pesar de ello no mereció la menor atención por parte de los biógrafos andalusíes, circunstancia que pone en duda la autenticidad de ese dato. Ibn Ḥārit e Ibn al-Faraḍī no lo incluyen entre sus biografiados

${ }^{4}$ Molina, L., "Técnicas de amplificatio en el Muqtabis de Ibn Hayyān [recurso electrónico]", Talia dixit: revista interdisciplinar de retórica e historiografía (desde la Antigüedad hasta el Renacimiento, 1 (2006), 55-79, disponible en http://hdl.handle. net/10261/3412 (consultado el 21 de junio de 2011). 
y todas las fuentes biográficas y cronísticas que lo mencionan se limitan a recoger, más o menos resumido, el relato que Ibn al-Qūtiyya hace de sus problemas con el emir al-Hakam. La única excepción es la de Ibn al-Abbār, quien conoce y menciona esa historia, pero aporta también algún dato más. La biografía que le dedica en la Takmila ${ }^{5}$ es la siguiente:

Ṭālūt b. ‘Abd al-Ŷabbār b. Muhammad b. Ayyūb b. Sulaymān b. Șālih b. alSamh al-Ma āfirī, de la gente de Córdoba. Residía en ella cerca del cementerio al que dio nombre, en cuyo interior se encuentra la mezquita conocida asimismo por su nombre. Tío materno del alfaquí Muhammad $b$. 'Tsà al-A ${ }^{e}$ s̀à $^{6}$ y pariente del alfaquí Abū Șāliḥ Ayyūb b. Sulaymān b. Șālih b. Garīb ${ }^{7}$, al ser este Garīb hermano de Tāalūt. Fue uno de los que transmiten de Mālik b. Anas y de sus análogos.

Más tarde participaría con los habitantes del arrabal en el alzamiento contra el emir al-Ḥakam b. Hišām, tras lo cual huyó y se ocultó -asunto éste en el que le sucedió una historia asombrosa, relatada por Ibn al-Qūtiyya y por otro-, hasta que al-Ḥakam dio con él, aunque acabó perdonándolo.

Tenía renombre por su religiosidad y saber, destacando especialmente en el cultivo del fiqh.

Lo menciona Ibn Ḥayyān y se emplean también datos de al-Rāzī y de otros semejantes.

La noticia la he leído de puño y letra de Abū Muhammad ibn Nūḥ ${ }^{8}$.

No es conocido entre los transmisores de Mālik.

La estructura de esta breve biografía responde perfectamente a lo que conocemos de la forma en la que Ibn al-Abbār elaboró su Takmila $^{9}$. Un personaje que, aunque perteneciente al mundo de los ulemas por su formación, no ha pasado a formar parte del repertorio

${ }^{5}$ Ibn al-Abbār, al-Takmila li-kitāb al-Șila, 'Abd al-Sallām al-Harrās (ed.), Casablanca, s.a., I, 276, n. ${ }^{\circ} 951$.

6 Tradicionista cordobés fallecido en el año 221 o 222 (836-837); Marín, M., "Nómina de sabios de al-Andalus", en M. Marín (ed.), EOBA, I, Madrid, 1988, 23-182, n. ${ }^{\circ} 1291$.

7 Alfaquí y gramático cordobés, de origen jienense, nacido en el 228/842 y fallecido en el 302/914; Marín, "Nómina", n. ${ }^{\circ} 298$.

8 Abū Muhammad Ayyūb b. Muhammad b. Wahb al-Gāfiqīi. Nacido en Zaragoza en el 486/1093, tras la conquista cristiana de la ciudad en el 512/1118 inició una larga peregrinación por diversas ciudades del Levante, instalándose finalmente en Valencia en el 517/1123. Allí falleció en el 576/1180. Según Ibn al-Abbār (Takmila, I, 166-7, n. ${ }^{\circ}$ 533), Ibn Nūh había redactado un compendio de notas históricas que él mismo utilizó como fuente; Biblioteca de al-Andalus, 4, 340-342, n. ${ }^{\circ} 921$.

9 Ávila, M.L., "El método historiográfico de Ibn al-Abbār", en Marín (ed.), EOBA, I, 555-583.

Al-Qantara XXXII 2, julio-diciembre 2011, pp. 533-557 ISSN 0211-3589 
de los biografiados en las obras canónicas (en su caso le hubiera correspondido cronológicamente la de Ibn al-Faraḍī), es incorporado por Ibn al-Abbār a ese repertorio al incluirlo en la Takmila, para lo cual debe recurrir a fuentes no biográficas. Según el testimonio de Ibn al-Abbār, la fuente utilizada es Ibn Hayyān, a la que se ha añadido algún dato tomado de al-Rāzi ${ }^{10}$ y de otros; la mención a los relatos de Ibn al-Qūtiyya y de «otro» debe ser entendida en el sentido de que ésas son las fuentes de las que tomó la noticia Ibn Ḥayyān, no que el propio Ibn al-Abbār las consultara directamente. Como conocemos perfectamente los textos de Ibn al-Qūtiyya e Ibn Ḥayyān, no es difícil delimitar qué información de la recogida en esta biografía procede de al-Rāzì: apenas el nombre completo de Ṭālūt, su parentesco con un par de ulemas $\mathrm{y}$, tal vez, la caracterización del personaje como alfaquí y persona religiosa y sabia. La frase final, la duda sobre sus contactos con Mālik, es muy probable que haya que atribuirla al mismo Ibn al-Abbār.

Lo cierto es que, analizada con detenimiento la única fuente que sabe de Țālūt algo más de lo que de él contaba Ibn al-Qūțiyya, comprobamos que, de no ser por esas mínimas indicaciones de al-Rāzī referidas a datos onomásticos y familiares, estaríamos tentados de sospechar que el personaje de Țālūt era un invento de Ibn al-Qūțiyya. Parece que no es así, pero no es menos cierto que su relevancia dentro del mundo de los ulemas cordobeses fue inapreciable.

En la narración que nos va a servir para trazar la transmisión y evolución del texto de Ibn al-Qūtịya que hemos elegido, Țālūt aparece como protagonista de una historia enraizada en motivos tradicionales: la inesperada fidelidad a la amistad por parte de un personaje marginal o secundario - en este caso, un judío, un infiel situado fuera de la comunidad musulmana- y la traición cobarde del individuo que representa la «normalidad» y que, a priori, presenta todos los rasgos pertinentes para constituirse en depositario de confianza y en refugio seguro: un antiguo amigo, de noble posición social - un visir-y piadoso musulmán. Țālūt $b$. 'Abd al-Ŷabbār, perseguido por haber participado en el alzamiento que se produce en el arrabal de Córdoba contra el emir al-Hakam, se refugia en casa de un judío vecino suyo. Oculto allí durante un año, siente finalmente que ya ha representado bastante carga para su huésped y, en contra de la opinión

${ }^{10}$ No podemos conocer a cuál de los dos al-Rāzī (Aḥmad o su hijo ‘̄isà) se refiere. 
de éste, se acoge a casa del visir Abū 1-Bassām, con quien mantenía una buena amistad. Éste lo recibe con amabilidad, pero inmediatamente se dirige a presencia del emir al-Hakam y denuncia al fugitivo.

Conducido Țālūt ante el emir, éste le echa en cara su comportamiento, recordándole lo mucho que había hecho por él, los favores que le había dispensado y el gesto que había tenido con él al asistir al entierro de la mujer del alfaquí. La réplica es valiente, casi heroica, pues Țālūt, aun reconociendo toda su deuda moral con el emir, pone por encima sus deberes hacia su dios. En un desenlace tan improbable en la realidad como esperado en el desarrollo narrativo, el emir se muestra comprensivo ante su argumentación, reconoce sus errores y le concede el perdón completo e incondicionado, para, a continuación, echar en cara al visir Abū 1-Bassām su ruin comportamiento con Țâlūt, contraponiéndolo con la lealtad de un enemigo de la fe como era el judío.

La historia de Țālūt, el judío y el visir es un agregado de motivos literarios de amplia difusión. En ella convergen una variante del tema del «medio amigo», que sale en ayuda del protagonista cuando los supuestos amigos íntimos le fallan ${ }^{11}$, con el del sabio que se atreve a enfrentarse con el soberano en defensa de sus principios religiosos o morales y consigue no sólo salir indemne, sino también que el poderoso se humille y confiese sus culpas. La aparición de un no musulmán como aparente héroe de la historia no debe llevarnos a engaño; la figura del judío es únicamente el contrapunto a la del musulmán que traiciona la confianza de Țālūt. La generosidad del judío no tiene otra función que la de magnificar la felonía de Abū 1-Bassām; una vez que eso ha quedado de manifiesto, el personaje desaparece completamente del relato y no sabemos nada más de él. De hecho el relato resulta insatisfactorio desde un punto de vista narratológico precisamente por la interrupción de la trama referida al personaje del judío; el desarrollo natural de la historia requeriría un desenlace adecuadamente dramático que dejase resuelto ese hilo argumental: el judío, apresado al mismo tiempo que Ṭālūt, sería lleva-

${ }^{11}$ En realidad no existe conexión argumental directa entre el cuento del «medio amigo», de origen oriental y que pasó a la literatura europea a través de la Disciplina clericalis de Pedro Alfonso, y la historia de Tālūt, (Schwarzbaum, H., "International Folklote Motifs in Petrus Alphonsi's Disciplina Clericalis", Sefarad, XXI (1961), 283289; Lacarra, M.J., Cuento y novela corta en España. I: Edad Media, Barcelona, 1999, 135-141).

Al-Qanțara XXXII 2, julio-diciembre 2011, pp. 533-557 ISSN 0211-3589 
do ante el emir para ser castigado por ocultar a un fugitivo; tras los pertinentes momentos de miedo y angustia, el generoso transgresor recibiría el perdón del soberano $\mathrm{y}$, tal vez, sería espléndidamente recompensado. Porque la alternativa a ese final feliz sería un desenlace turandotiano: el judío es condenado a muerte y ejecutado como primer paso en la terrible venganza del soberano, pero acto seguido el destino de Țālūt se desvía de su trágico final y el desencuentro entre el emir y él concluye en jubilosa reconciliación al demostrar y comprender, respectivamente, que el acatamiento de los mandatos divinos está por encima de cualquier otra obligación. Final trágico, majestuoso y cínico que no cuadra en absoluto con el tono general del relato de Ibn al-Qūtiyya, rebosante de actos de bondad, pequeñas mezquindades y galardones justos: premio para quien se ha portado bien y para el infame, escarmiento (pero sin excesos: el castigo es únicamente su alejamiento de la munífica persona del emir). También en ese reparto el judío permanece completamente olvidado ${ }^{12}$.

Pero el punto de vista desde el que nos vamos a acercar a este relato no va a ser la búsqueda de antecedentes ni paralelos literarios o folklóricos en las narraciones de tipo anecdótico que pueblan las crónicas y los diccionarios biográficos, sino que hemos de enfocar la cuestión desde lo estrictamente historiográfico, con el objetivo de trazar el stemma que recoja y organice las distintas versiones que de este texto, supuestamente salido de la pluma de Ibn al-Qūtiyya, recogen esos dos tipos de fuentes.

Y si hemos utilizado un término proveniente de la ecdótica, como es stemma, es porque vamos a recurrir a las técnicas de la crítica textual para conseguir nuestros fines. Ello es posible gracias a la circunstancia bien conocida de que los autores árabes, y muy especialmente los cronistas y biógrafos, construyen habitualmente sus obras, en los pasajes en los que se basan en fuentes escritas, por medio de la acumulación de citas textuales, que respetan casi religiosamente la literalidad de los textos que reproducen. Es evidente que ese respeto a la fuente no es siempre total y en ocasiones el autor

${ }^{12}$ Curiosamente al-Dahabī, al incluir en sus Siyar a 'ām al-nubalā' esta historia (v. infra, p. 483), parece opinar también que la figura del judío merece un tratamiento más generoso y decide darle un papel en la conclusión del relato: el emir lo recompensa espléndidamente y él, al comprobar el magnífico trato que se le dispensa, decide convertirse al Islam. De esta forma, lo que pudo haber sido tragedia y se había quedado en melodrama pasa a quedar reducido a cuento infantil de final feliz y moraleja meliflua. 
introduce modificaciones voluntarias, modificaciones que, para el propósito que nos ocupa, son perfectamente asimilables a los cuatro tipos de error de copia que sirven a la crítica textual para efectuar la recensio de los distintos testimonios: errores por adición, omisión, cambio de orden y sustitución; pero, incluso en el caso de que lo que persiga un compilador sea una copia exacta de la fuente de la que se está bebiendo, es inevitable que surjan errores involuntarios, puesto que el autor se comporta en una fase determinada de su proceso creativo como simple copista, proclive, por tanto, a cometer los típicos e inevitables errores en los que todo copista incurre. En definitiva, el texto que un autor incorpora a su obra copiándolo de una fuente precedente sufre una transformación de entidad muy variable que lo convierte en una versión dotada de características propias, características que se materializan en una serie de variantes que constituyen sus signos de identidad. Cuando esta versión se convierte, a su vez, en fuente de otro autor, esos signos de identidad pasan a esta tercera obra, que añade otros de su propia cosecha. El análisis de todas esas variantes es lo que nos va a permitir reconstruir la estructura de filiación de las diversas versiones de un texto, que en este caso es la historia de la huida y posterior perdón del alfaquí Țālūt b. 'Abd al-Ŷabbār.

La elaboración de este stemma puede tener utilidad también para identificar y corregir errores en la transmisión de los textos - objetivo básico cuando esta metodología se aplica en su campo natural, la crítica textual - , pero aquí es una utilidad marginal, aunque no por ello despreciable. La gran diferencia entre el stemma ecdótico y el historiográfico es que el primero es un medio para la consecución de un objetivo, que no es otro que la identificación o reconstrucción del arquetipo o del original, del texto salido de la mano del autor, mientras que el stemma historiográfico es un fin en sí mismo, ya que lo que se persigue es la fijación de la estructura del sistema de relaciones que articula las vías de transmisión de una noticia determinada, recogida, a partir de una fuente original, en distintas obras. El stem$m a$ es la representación gráfica de dicha estructura $\mathrm{y}$, por lo tanto, constituye el punto final del proceso. 


\section{La tradición textual}

Las fuentes que reproducen el texto de la historia de Țālūt son:

Ibn al-Qūṭiyya (m. 367/977), Ta'rỉj Iftitāḥ al-Andalus (Madrid, 1926, 53-55; trad. 42-44).

Ibn Hayyān (377-469/987-1076), al-Muqtabis (ed. M.'A. Makkī, Riyad, 1424/2003, 166-169; trad. M.'A. Makkī y F. Corriente, Crónica de los emires Alhakam I y 'Abd al-Rahmān II, Zaragoza, 2001, $75-78)^{13}$.

'Iyāạ (476-544/1088-1149), Tartīb al-madārik (ed. M. Bencherifa, et al., Rabat, 1983, III, 340-342) .

'Abd al-Wāḥid al-Marrākušī (581-post 621/1185-post 1224), alMu'ŷib (ed. M. al-'Uryān, Cairo, 1383/1963, 45-47) .

Ibn Sā̄d (610-685/1213-1286), al-Mugrib (ed. Š. Ḍayf, Cairo, 1964, I, 43) .

Ibn 'Abd al-Malik (634-703/1237-1303), al-Dayl wa-l-takmila (ed. I. 'Abbās, Beyrut, 1964, IV, 150-152) .

Al-Nuwayrī (677-733/1279-1333), Nihāyat al-arab (ed. M. Gaspar Remiro, Granada, 1917, 39; trad., 34) .

Al-Dahabī (673-748 ó 753/1274-1348 ó 1352), Siyar a lām alnubalā' (Beyrut, 1406/1986, VIII, 258-259) .

Al-Maqqarī (986-1041/1577-1632), Nafḥ al-țīb (ed. I. 'Abbās, Beyrut, 1968, II, 639) .

Casi siete siglos separan al más antiguo y al más tardío de los autores; los orígenes geográficos de los nueve son muy diversos y se reparten entre al-Andalus, el Magreb y Oriente; en la relación aparecen tanto obras puramente cronísticas como diccionarios biográficos.

13 En un pasaje que se halla unas páginas antes del aquí comentado (p. 156-157/6869) Ibn Hayyān reproduce un texto muy breve en el que resume la historia de Tāâtūt en términos muy semejantes a los que empleará posteriormente en el relato extenso. Esto no resultaría en modo alguno extraño (hay otros casos en los que el Muqtabis reproduce dos veces una cita, como, por ejemplo, algunas noticias sobre los visires de "Abd al-Raḥmān II en 294-295/183-184, que podemos hallar con idénticas palabras en el siguiente fragmento del Muqtabis, el publicado por Makkī en 1973, 29-30), si no fuera porque el pasaje está lleno de contradicciones desde el punto de vista historiográfico. Ibn Ḥayyān cita como fuente a Ibn al-Qūtiyya y, en efecto, el relato que le atribuye coincide en líneas generales con el que luego reproducirá in extenso. Sin embargo, hay un dato sorprendente: el amigo desleal no es el visir Abū Bassām sino otro visir bien conocido, al-Iskandarānī; para acabar de complicar la cuestión, tras finalizar esta cita Ibn Ḥayyān vuelve a recurrir a Ibn al-Qūtiyya para refutar lo que acaba de decir y asegurar que el protagonista fue Abū Bassām y no al-Iskandarānī. 
En otras palabras, la muestra de la que disponemos es variadísima y demuestra hasta qué punto esta narración perduró en el tiempo y se difundió por todo el ámbito del Islam. Algo un tanto sorprendente dado el escaso valor histórico del relato, que no aporta ninguna información relevante acerca del acontecimiento histórico en el que se enmarca la anécdota, la revuelta del Arrabal de Córdoba. En el caso de los diccionarios biográficos puros —Madārik y Dayl - la inclusión en ellos del relato está justificada porque, como se ha dicho con anterioridad, lo único que conocemos de Țālūt es lo que relata Ibn al-Qūtiyya en este pasaje y, por lo tanto, todo biógrafo que quisiera incluir en su repertorio el nombre de Țâlūt se veía obligado a utilizar ese relato, pues no disponía de más información sobre él ${ }^{14}$. Pero la pervivencia de la historia de Țâlūt en crónicas y en obras que funcionalmente operan como crónicas no puede ser explicada tan fácilmente y nos hace sospechar que en dicha historia tiene que haber elementos de algún tipo (ejemplarizantes, morales, argumentales) lo suficientemente atractivos para captar la atención de tantos y tan diversos autores.

Es indudable que Ibn al-Qūtiyya es el arquetipo del que todos los demás derivan, no sólo ni principalmente porque sea el más antiguo, sino porque alguno de los que mencionan la fuente de la que están bebiendo da su nombre (Ibn Hayyān, 'Iyāẹ e, indirectamente, Ibn 'Abd al-Wāḥid, que cita a Ibn Ḥayyān). Por ello tomaremos el texto de Ibn al-Qūtiyya conservado en el ms. de París como punto de partida y marcaremos en él una serie de loci critici, pasajes en los que se concentran las más numerosas e importantes variantes que aparecen en las obras que lo reproducen (marcados con negrita):

${ }^{14}$ En realidad las motivaciones de 'Tyāḍ e Ibn 'Abd al-Malik debieron ser muy distintas. El ceutí incluiría la biografía de Ṭālūt porque en sus Madārik, dedicados en exclusiva a los alfaquíes mālikíes, no podía omitir a un personaje que había sido supuestamente discípulo de Mālik; en cuanto a Ibn 'Abd al-Malik, en su afán por continuar y completar los diccionarios de Ibn al-Faraḍi e Ibn Baškuwāl, recurre a todo tipo de material para ampliar la nómina de personajes biografiados; en el caso de Țālūt, encuentra en una crónica informaciones sobre un personaje que, de ser cierto lo que decía de él ese relato, tenía méritos suficientes para haber figurado en la obra de Ibn al-Faradīi, (Carballeira, A.M., "La introducción de Ibn 'Abd al-Malik al-Marrākušī a su al-Dayl wa-l-Takmila", en M.L. Ávila y M. Fierro (eds.), EOBA, X, Biografías almohades II, Madrid-Granada, 2000, 195-222). 
وكان في جملة من أجلب عليه في الربض طالوت بن عبد الجبار المعافري، وهو أحد من روى عن ماللك ونظر ائه من أهل العلم.

فلما وقعت الوقيعة فر عن داره وكان مسكنه بالمدينة يجاور المسجد والحفرة المنسوبين إليه، فاستتر

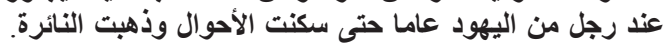

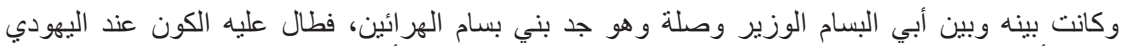

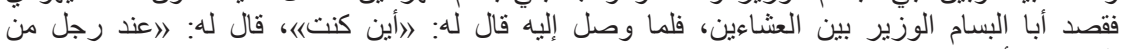
اليهودن)، فأمنه وسكند.

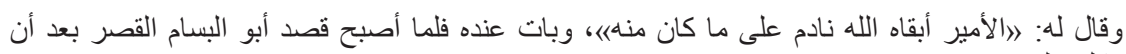
وكل عليه من يحرسه.

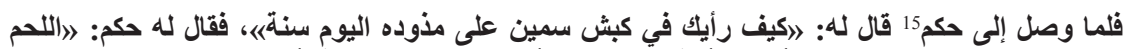

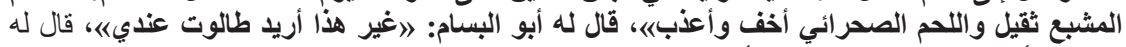

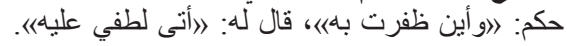

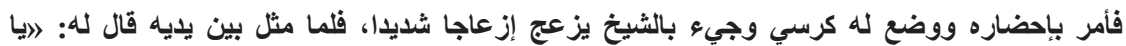

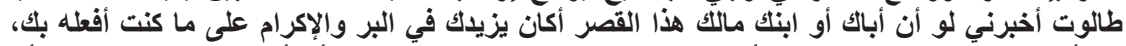

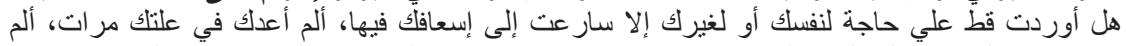

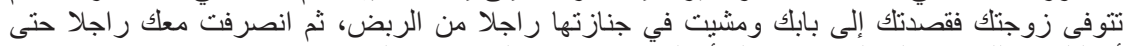

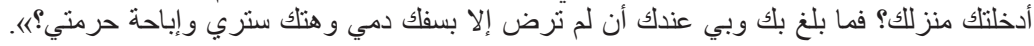

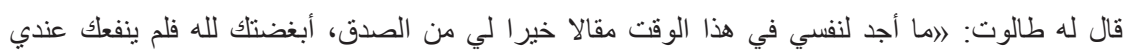
كلما صنعته في نسياء.

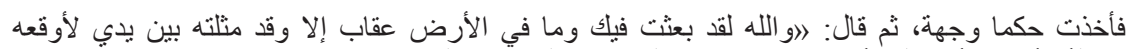

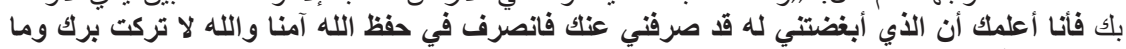

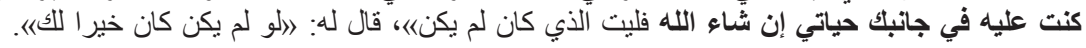

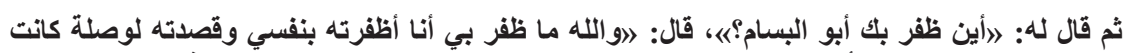

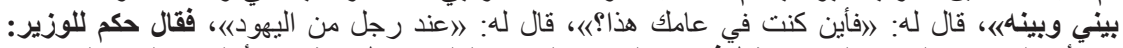

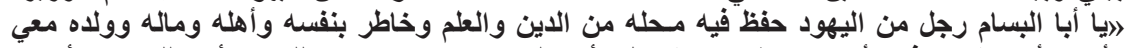

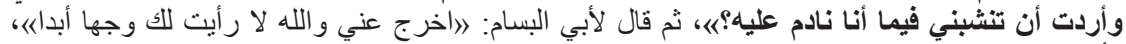

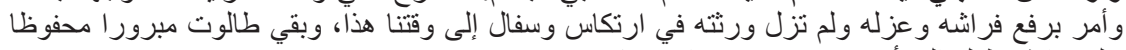

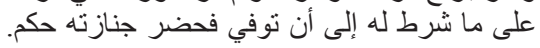

De los restantes ocho textos que reproducen la historia de Tầlùt sólo tres lo hacen de forma íntegra (Muqtabis, Tartīb y Dayl), mientras que los otros cinco ofrecen únicamente un resumen más o menos amplio. Por ello en una primera fase vamos a efectuar la collatio sobre la cuatro versiones amplias (las tres mencionadas más la de Ibn al-Qūtịyy), dejando para más adelante la labor de ubicar las restantes obras en el stemma que obtengamos en esta primera etapa.

${ }^{15}$ En este relato el emir es llamado en todas las ocasiones Hakam, sin artículo. En el resto del Iftitāh se emplean indistintamente las dos formas.

Al-Qanțara XXXII 2, julio-diciembre 2011, pp. 533-557 ISSN 0211-3589 


\section{Loci critici}

a) Țâlūt huye de su casa, cercana a la mezquita que lleva su nombre:

ابن القوطية: فلما وقعت الوقيعة فر عن داره وكان مسكنه بالمدينة يجاور المسجد والحفرة المنسوبين إليه.

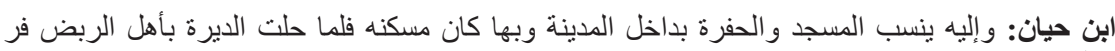

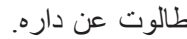
عياض: و إليه ينسب المسجد و الحفرة بداخل مدينة قرطبة و هناك كان مسكنه.

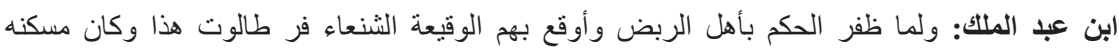
بالمدينة مجاور المسجد والحفرة المنسوبين إليه.

El orden de las dos frases que forman este párrafo y su redacción muestran con claridad que las versiones de Ibn al-Qūtiyya y de Ibn 'Abd al-Malik coinciden y se separan conjuntamente de las de Ibn Hayyān e 'Tyāḍ, emparentadas entre sí.

b) Se refugia en casa de un vecino judío:

$$
\begin{aligned}
& \text { ابن القوطية: فاستتر عند رجل من اليهود عاما حتى سكنت الأحوال وذهبت النائرة. } \\
& \text { ابن حيان: فاستخفى عند رجل من اليهود جير انه وثق بها، فتقبله اليهودي أحسن قبول ولئ وحطن مكان تواريه }
\end{aligned}
$$

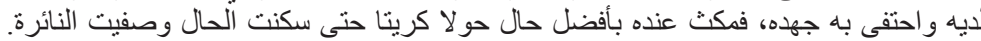

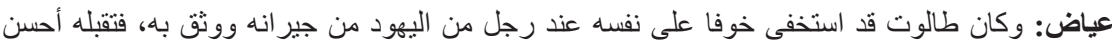

$$
\begin{aligned}
& \text { قبول، ومكث عنده بأفضل حال حو لا حتى طفئت النائرة. } \\
& \text { ابن عبد الملك: ولجأ إلى رجل من اليهود فاختفى عنده عاما كاملا حتى مل المقام عنده وسكنت الأحوال }
\end{aligned}
$$

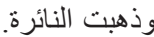

De nuevo resulta evidente la existencia de dos versiones divergentes: la de Ibn Hayyān e 'Iyāḍ, notablemente amplificada, y la de Ibn al-Qūtịya e Ibn 'Abd al-Malik, que coinciden al silenciar la condición de vecino del judío, al emplear para «año» el término 'ām, en lugar del hawl de Ibn Hayyān e 'Iyāọ, y al usar el verbo dahabat frente al șuffiyat/tufi'at de los otros para regir la palabra al-nā'ira. 
c) Abū 1-Bassām informa a al-Ḥakam de que tiene a Ṭālūt en su poder:

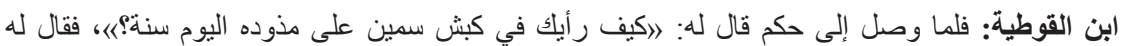

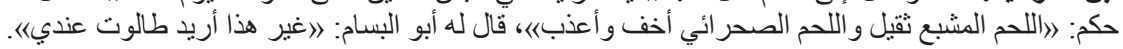
ابن حيان: فقال للأمير: 》اما رأيك في عجل سمين عاكف على مذوده منذ سنة تلذ مطعمه؟؟)، فقال له: اأنا

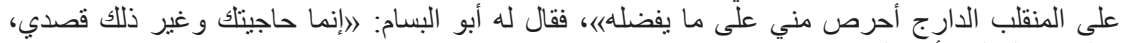

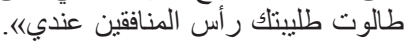

عياض: فقال للأمير: 》اما رأيك في عجل سمين عاكف على مذوده منذ سنة يلذ مطعمه؟، هذا طالوت رأس المنافقين عندي《.

ابن عبد الملك: فلما وصل إلى الحكم قال له: 》ها تقول في كبش مسمن لم يفارق مزوده عاما كاملا؟)؛

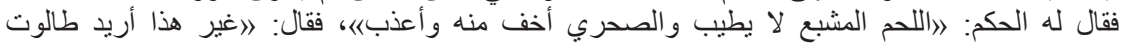
عندي《.

Este pasaje viene a confirmar lo ya apuntado en los dos anteriores: la existencia de dos versiones emparentadas entre sí, pero claramente diferenciadas. Ibn al-Qūtiyya e Ibn 'Abd al-Malik son representantes de una de ellas e Ibn Hayyān e 'Iyād, de la otra. Los pasajes siguientes lo corroborarán de forma definitiva.

d) Al-Ḥakam reprocha su traición a Ṭālūt:

ابن القوطية: فأمر بإحضاره ووضع لله كرسي وجيء بالثيخ بز عج إزعاجا شديدا، فلما مثل بين يديه قال له: اليا طالوت أخبرني لو أن أبالك أو ابنك مألك هذا القصر أكاء أكان يزيدك في البر والإكرام على ما كنت

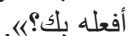

ابن حيان: فجلس على كرسي بباب مجلسه فجمع من نفسه وجعل يفتل سباله تغيظا على طالوت، فلم يلبث

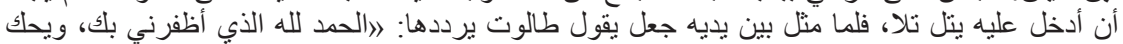

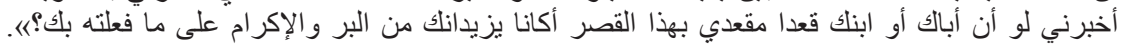
عياض: فجلس على كرسي بباب مجلسه يثوقد غيظا عليه، فلم بلبث أن أدخل طالوت عليه فجعل بيتقر عه أنه

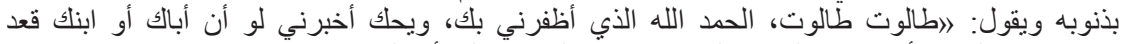

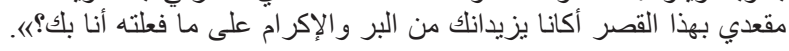

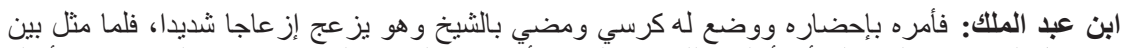

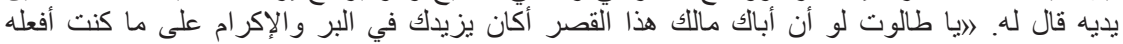
معلكיז队. 
e) Perdón de al-Ḥakam:

ابن القوطية: الأنا أعلمك أن الذي أبغضنتي له قد صرفني عناءك، فانصرف في حفظ الله آمنا، والله لا

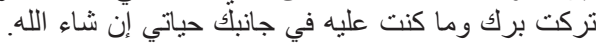

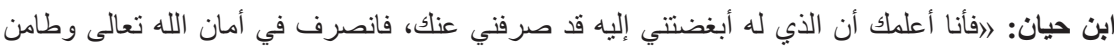

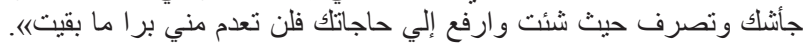

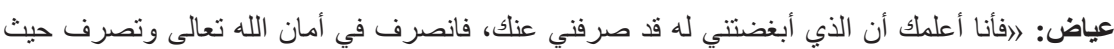

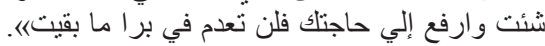

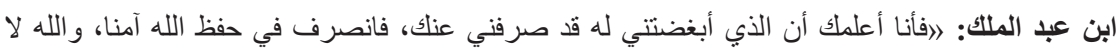

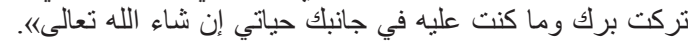

f) Al-Ḥakam pregunta a Ṭālūt acerca de las circunstancias de su captura:

ابن القوطية: ثم قال له: 》أين ظفر بك أبو البسام؟)، قال: 》اوالله ما ظفر بي أنا أظفرته بنفسي وقصدته لو لوصلة كانت بيني وبينهاه.

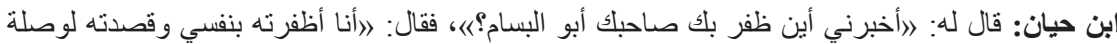

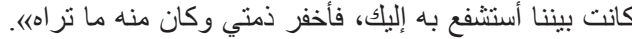

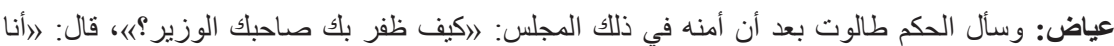

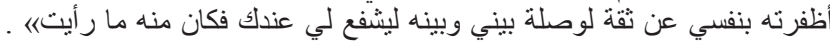

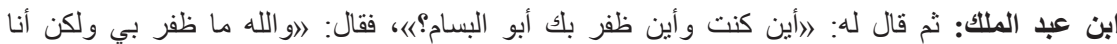
أظفرته بنفسي وقصدته لوصلة كانت بيني وبين والمبنه

\section{g) Reproches a Abū 1-Bassām:}

ابن القوطية: فقال حكم للوزير: إيا أبا البسام رجل من اليهود حفظ فيه مـله من الدين والعلم وخاطر

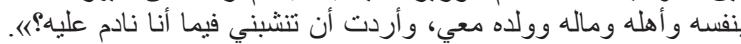

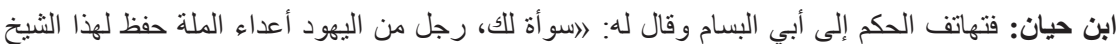

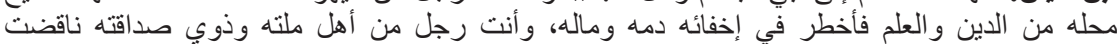

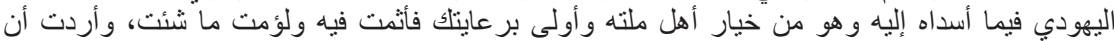

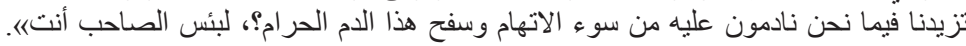

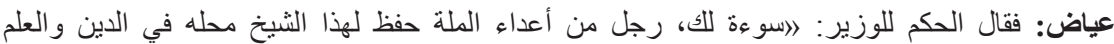

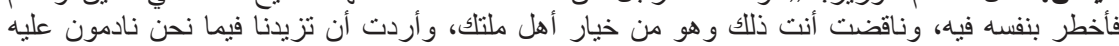

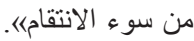

ابن عبد الملك: فقال الحكم للوزير: إأبا البسام رجل من اليهود حفظ فيه محله من الدين و العلم وخاطر فيه بنفسه وأهله وولده معي، وأنت أردت أن تنشبني فيما أنا نادم عليه اليوم ولئ وعلى مثله؟به.

Al-Qantara XXXII 2, julio-diciembre 2011, pp. 533-557 ISSN 0211-3589 
Sin que este pasaje contradiga lo que venimos observando hasta ahora, es decir, la existencia de dos versiones claramente diferenciadas, hay sin embargo datos que llaman la atención, pues en un par de lugares el texto de 'Iyāọ se acerca más a la versión de Ibn al-Qūṭiyya y de su fidelísimo seguidor Ibn 'Abd al-Malik: el primero es la frase introductoria de la intervención del emir, que es la misma en todas las fuentes («dijo al-Hakam al visir») excepto en el Muqtabis, donde Ibn Ḥayyān da más dramatismo a la escena, al tiempo que nombra al interpelado por su kunya, no por su cargo, como hacen las otras fuentes («al-Ḥakam se dirigió a gritos a Abū l-Bassām diciéndole»). El segundo lugar lo hallamos en la frase «se puso en peligro a sí mismo, a su familia, a su hacienda y a sus hijos», en la que coinciden, como es habitual, Ibn al-Qūtiyya e Ibn 'Abd al-Malik (éste omite «su hacienda»), mientras que Ibn Hayyān la transforma en «puso en peligro su sangre y su hacienda al ocultarlo»; 'Iyāḍ, por su parte, aunque resume radicalmente, se acerca más a la primera («se puso en peligro a sí mismo»). Son dos datos muy poco significativos, pero apuntan en un sentido claro: 'Iyāḍ no estaría siguiendo el texto del Muqtabis, sino que utilizaría la misma fuente que Ibn Hayyān, fuente en la que ya se hallarían la mayoría de las modificaciones que se hicieron al relato original de Ibn al-Qūtiyya, pero faltarían algunas, las introducidas por el propio Ibn Hayyān. Más adelante comentaremos de pasada esta hipótesis.

La conclusión que podemos extraer de esta colación de versiones es obvia: las cuatro están textualmente emparentadas entre sí y, por tanto, tienen un mismo origen, pero las variantes que presentan delimitan con nitidez dos familias de transmisión, una que incluye el Iftitāh de Ibn al-Qūtiyya y el Dayl de Ibn 'Abd al-Malik, y otra representada por el Muqtabis de Ibn Ḥayyān y el Tartīb de 'Iyāọ. En circunstancias normales no tendríamos ningún problema en trazar el stemma de este grupo de textos: dado que el pasaje proviene indudablemente de Ibn al-Qūtiyya (a él se lo atribuyen nominatim Ibn Hayyān e 'Iyāạ), podríamos suponer que la versión recogida en el manuscrito de París del Iftitāh es la original, que en ella se basaría directamente el Dayl y que la variante amplificada que representan Muqtabis y Tartīb deriva de un subarquetipo, en el que se habría producido dicha amplificación; por razones cronológicas, ese subarquetipo no puede ser Tartīb, de modo que o bien es Muqtabis, con lo que Tartīb derivaría de él, o bien es una obra desconocida de la que tomarían sus versiones independientemente Muqtabis y Tartīb. 
Esta estructura de relaciones textuales es sencilla, plausible y razonable y sería perfectamente aceptable si no fuera porque frente a ella se alza la muy difundida teoría de que la versión del Iftitāh registrada en el manuscrito de París no es la definitiva, sino un borrador o unos «apuntes de clase» recopilados por algún alumno de Ibn al-Qūtiyya. La redacción final no se habría conservado más que a través de las citas que de ella hacían diversos autores posteriores, como serían, en el caso del pasaje que nos ocupa, Ibn Hayyān e 'Tyāḍ. A la vista de todo esto la cuestión que nos hemos de plantear es la existencia de esa «redacción larga» del Iftitāh, admitida hasta ahora de forma tan unánime como superficial. Pero, antes de entrar en la argumentación final sobre la cuestión, bueno será que intentemos obtener más datos del análisis del resto de las fuentes que reproducen la historia de Țâlūt.

\section{Las fuentes secundarias}

Además de las cuatro versiones íntegras de la historia de Țālūt que acabamos de analizar, contamos con otras cinco en las que se somete el texto a un proceso de síntesis más o menos riguroso. De ellos podemos descartar el testimonio de Ibn Sa ${ }^{e} \overline{1} d$ en su Mugrib, ya que extracta de manera tan radical que el texto resultante es inválido para cualquier confrontación textual por su extrema concisión ${ }^{16}$. Los otros cuatro textos son, como ya se ha señalado antes, el $M u^{\prime} \hat{y} i b$ de al-Marrākuš̄î, la Nihāya de al-Nuwayrī, las Siyar de al-Dahabī y el Nafh de al-Maqqarī. Sin llegar a los extremos de la de Ibn Sa īê, lo cierto es que en estas versiones las semejanzas con las dos redacciones que hemos identificado anteriormente se han difuminado sensiblemente, tanto por su condición de resúmenes como por un cierto grado de reelaboración que todas ellas han experimentado. Sin embargo perduran vestigios que nos permiten adscribirlas a una $u$ otra familia.

${ }^{16}$ A pesar de lo cual no hay dudas de que su fuente es el Muqtabis, tanto porque todas las secciones cronísticas del Mugrib referidas al período omeya son deudoras casi en exclusiva de la obra de Ibn Hayyān como porque el único dato significativo que aparece en su relato, la identificación del visir traidor con al-Iskandarānī, en lugar de Ibn Bassām, es un rasgo personalísimo de la segunda versión que incluye el Muqtabis.

Al-Qanțara XXXII 2, julio-diciembre 2011, pp. 533-557 ISSN 0211-3589 
Siyar

El relato de al-Dahabī en sus Siyar está emparentado sin duda alguna con los de Ibn al-Qūtiyya e Ibn 'Abd al-Malik ${ }^{17}$ :

- En el locus 'c, cuando Abū 1-Bassām anuncia al emir que tiene a Ṭālūt en su poder, al-Dahabī emplea la expresión «carnero cebado» (kab̌̌s samīn) cuando el visir alude metafóricamente a Țālūt y hace que al-Hakam replique que le parece una carne demasiado pesada (lahm țaqīl), rasgos propios de la versión de Iftitāh y Dayl, frente al «ternero cebado» ('îyl saminn) y el «más me gusta el animal que anda» de Muqtabis.

—En 'd, cuando al-Hakam reprocha a Țālūt su comportamiento, Siyar reproduce en los pasajes en los que hay divergencias la versión de Iftitāh: en el comienzo del párrafo Ibn al-Qūtiyya informa que el emir «ordenó que se presentara» (amara bi-ihdāri-hi), igual que hacen Dayl y Siyar, mientras que la pareja Muqtabis-Tartīb lo inician con la frase «se sentó en un sillón a la puerta de su salón» (ŷalasa áà kursī bi-bāb maŷlisi-hi); la mención a ese sillón o cadira la hallamos también en Ibn al-Qūtiyya y en Ibn 'Abd al-Malik —no en Siyar, que resume el pasaje-, pero en una redacción distinta: «se le colocó un sillón» (wudi'a la-hu kursī). Otro lugar en el que Siyar se acerca a Iftitāh-Dayl y se aparta de Muqtabis-Tartīb es en la interpelación que el emir hace a Ṭâlūt, cuando le pregunta si, de haber estado en el lugar del emir, el padre o el hijo de Țālūt hubieran sido con él tan generosos y afectuosos como lo había sido al-Hakam; Iftitāh, Dayl y Siyar utilizan la expresión «si tu padre o tu hijo hubieran gobernado este palacio/esta casa» (mālik hād ā l-qașr/malaka hādihi l-dār), Muqtabis y Tartīb lo expresan de otra forma: «si tu padre o tu hijo hubiesen ocupado mi

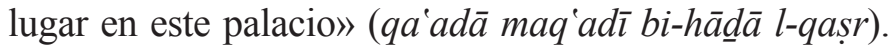

—El párrafo en el que al-Ḥakam concede su perdón a Ṭālūt ('e) vuelve a adscribir Siyar al grupo Iftitāh-Dayl, pues coincide con ellos en la redacción de la frase con la que el emir despide al alfaquí, «vete con la protección divina»:

$$
\text { ابن القوطية: 》افانصرف في حفظ الله آمنا، والله لا تركت برك وما كنت عليه في جانبك حباتي إن شاء }
$$

17 A pesar de que al-Dahabī es uno de los pocos autores que conocen y citan el $M u ' y ̂ i b$ de 'Abd al-Wāhịid, en esta ocasión no recurre a él (cfr. Siyar, XVII, 133; XIX, 547 y XX, 369 y $M u^{\prime} \hat{y} i b, 86,245$ y 262).

Al-Qanțara XXXII 2, julio-diciembre 2011, pp. 533-557 ISSN 0211-3589 


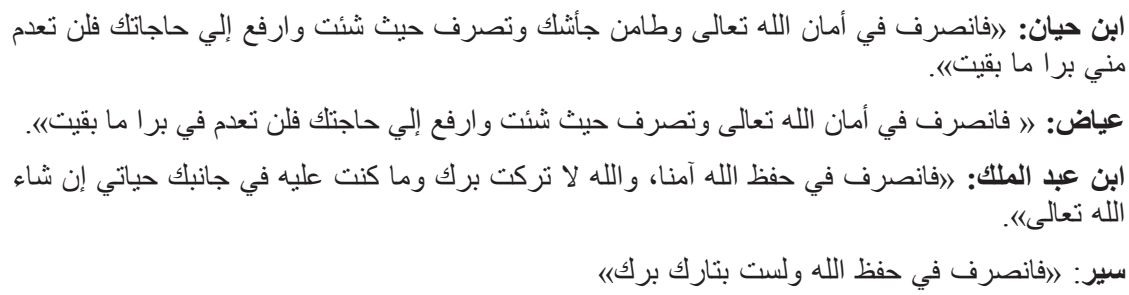

La confrontación del texto de Siyar con los de las cuatro fuentes extensas demuestra sin lugar a dudas que deriva de la versión conservada en Iftităh. En cuanto al grado de parentesco y las vías de transmisión entre ellas, poco se puede decir a la vista de los testimonios que poseemos. El origen de la versión hay que buscarla obviamente en el Iftitāh, pero ignoramos por qué vías llegó el texto a Dayl y Siyar; lo único que podemos descartar es la influencia de Dayl sobre Siyar, ya que éste conserva datos de Iftitāh que faltan en Dayl, como la voz que en el locus 'c utilizan Iftitạh y Siyar para «cebado» (samin), sustituida en Dayl por su equivalente musmin, o, en ese mismo párrafo, la forma independiente que tienen los dos continuadores de Ibn al-Qūtiyya de resumir el original, al convertir la frase «la carne cebada es pesada» en «la carne cebada no es de mi agrado» (Dayl) y «la carne es pesada» (Siyar). Cuando al-Hakam interpela a Țālūt, Siyar redacta el comienzo de su intervención con las mismas palabras que Iftităh, ( «Ṭālūt, infórmame, si tu padre o tu hijo...»), mientras que Dayl omite dos de ellas («Ṭālūt, si tu padre...»).

En conclusión, podemos afirmar que Dayl y Siyar derivan de forma independiente de Iftitāh.

\section{Mu'yib, Nihāya y Nafḥ}

Si se analizaran estos tres textos por separado sería difícil precisar a cuál de las dos familias de versiones habría que adscribirlos. Sólo el $M u^{\prime} \hat{y} i b$ aporta informaciones útiles al respecto, pues los otros dos llevan a cabo un resumen tan radical (Nihâya llega a condensar la historia en tres líneas) que cualquier rasgo diferenciador queda difuminado. Sin embargo, utilizando como referencia intermedia la información que podemos extraer de $M u \hat{y} i b$, se hace factible ubicar con ciertas garantías todas estas obras en el stemma. 
En efecto, la obra de 'Abd al-Wāḥid es la clave para vincular estos textos con la versión de Muqtabis, y lo es porque los leves puntos de contacto que podemos hallar al efectuar la confrontación textual se ven reforzados y confirmados por la sencilla razón de que 'Abd al-Wāḥid declara expresamente tomar la historia de Ibn Ḥayyān. Es éste un dato no tan definitivo como pudiera suponerse, pues siempre es aconsejable cierto escepticismo en este tipo de atribuciones, pero la presencia de otros indicios que apoyan la fiabilidad de esa afirmación nos permite otorgar alguna credibilidad a las palabras de 'Abd al-Wāhid y aceptar que su fuente fue el Muqtabis.

Los indicios textuales a los que nos referimos, los que acercan la versión de Mu'yib a la de Muqtabis, los hallamos en el comienzo de la historia, en los momentos que van desde que Țâlūt decide trasladarse a casa del visir Abū l-Bassām (convertido aquí en kātib) hasta que es recibido por éste. Este tramo del relato, que en Iftitāh es resuelto en un par de líneas y que en Muqtabis se ve sensiblemente amplificado, adquiere en $M u \hat{y} i b$ un desarrollo desproporcionado. En la versión de Ibn al-Qūțiyya recogida en el manuscrito de París, Țālūt decide abandonar la casa del judío cuando considera que ha estado allí demasiado tiempo y se presenta en casa del visir. Ibn Hayyān adorna un poco el relato y precisa que la razón por la que Țālūt había decidido irse era porque consideraba que ya había sido demasiada carga para el judío, a pesar de que éste le asegura que no es así y lo previene de los riesgos que va a correr si va a casa del visir. 'Abd al-Wāhid va más allá en esa dirección e introduce el discurso referido, haciendo que Țālūt le cuente a su anfitrión que el kâtib a cuya casa se dirige fue antiguo alumno suyo y que es una persona influyente que puede interceder por él, a lo que replica el judío advirtiéndole de que no se puede fiar de esa gente y asegurándole que para él no constituye carga alguna su presencia en su casa.

'Abd al-Wāhid se revela como un seguidor entusiasta de Ibn Hayyān, porque no sólo lo utiliza como fuente reconocida, sino que también imita su afán amplificador y añade su propia macrología a la de su modelo, de forma que el texto resultante guarda únicamente un remoto parecido textual con el original de Ibn al-Qūtiyya.

En la parte final de la historia, desde el momento en el que Țālūt es llevado a presencia de al-Hakam, 'Abd al-Wāhid modera sus afanes amplificadores y liquida el relato con brevedad, lo cual no le impide dejar en el texto su impronta personal, pues el diálogo entre 
el emir y Ṭâlūt que reproducen las otras fuentes no le parece adecuado y lo reemplaza con otro, íntegramente inventado por él, en el que Ṭālūt parece negar la acusación de haber participado en la revuelta, pues argumenta que alguien que, como él, ha oído de boca de Mālik la máxima «un gobierno inicuo durante largo tiempo es mejor que una sola hora de discordia (fitna)» ${ }^{18}$, no puede alzarse contra el soberano. El relato concluye con el habitual perdón del emir y la reprimenda a Abū 1-Bassām, que es destituido del cargo de visir (aunque con anterioridad 'Abd al-Wāhid nos lo había presentado únicamente como kātib).

Es justamente esta parte final la que nos suministra los datos necesarios para entroncar las dos versiones que nos quedan, Nihāya y Nafh. Como ya se ha señalado antes, ambos textos resumen sin muchos miramientos la fuente a la que recurren, de forma que todo vestigio textual de su origen último, la obra de Ibn al-Qūtiyya, ha desaparecido tras pasar por repetidos procesos de abreviación y amplificación simultáneas. Pero, si de la versión original del texto no queda ya nada en Nihāya y Nafh, su antecedente inmediato ha dejado huella inconfundible en ellos; ese antecedente es $M u \hat{y} i b$ (o alguna obra muy emparentada con él). El párrafo que constituye el meollo del relato de Nihāya y Nafh es justamente el que cierra la narración de $M u^{\prime} y \hat{i} i b$, desde el momento en el que el emir hace que se presente Ṭālūt hasta el final, pasaje en el que 'Abd al-Wāḥid da rienda suelta a su creatividad para insertar - y adaptar toda la narración a ella — la frase atribuida a Mālik. Las versiones de $M u^{\prime} \hat{y} i b$ y Nafh son idénticas en ese pasaje, mientras que en la sección anterior Nafh condensa el texto hasta dejar en cuatro líneas la docena que emplea Mu'yib. En cuanto a Nihāya, construye su conciso relato extrayendo algunas frases de su fuente, que, si no es el mismo $M u \hat{y} i b$, ha de ser una obra muy emparentada con él.

En definitiva, aunque ni Nihāya ni Nafh conserven rasgos peculiares que nos permitan adscribirlos a uno de los dos grupos, el de seguidores de Iftitāh o el de emparentados con Muqtabis, a través de su muy íntima vinculación con $M u$ ỳib podemos situarlos en la misma rama que éste, es decir, en la de Muqtabis. En cuanto a la relación

${ }^{18}$ No está documentado este dicho atribuido a Mālik. Sin embargo, en parecidos términos reza una frase atribuida a 'Amr b. al- ${ }^{\prime} \bar{A} s$ y que aparece recogida en incontables obras, como la Bahŷat al-maŷălis de Ibn 'Abd al-Barr (al-Jūlī (ed.), El Cairo, s.f., I, 333): «Un imán injusto y tiránico es mejor que una fitna pertinaz». 
entre los tres textos, es indudable que Nihāya y Nafh comparten una fuente común, puesto que el autor más tardío de los dos, al-Maqqarī (m. 1041/1632), conserva una versión mucho más amplia que la de al-Nuwayrī (m. 733/1333), lo que implica que ninguno puede ser fuente del otro. La posibilidad de que la fuente común a ambos sea $M u$ yìib es bastante plausible y dependerá del crédito que otorguemos a las palabras de 'Abd al-Wāhid: si aceptamos que el texto lo ha tomado directamente de Muqtabis, hemos de colegir que las modificaciones que presenta la versión de $M u^{\prime} \hat{y} i b$ con respecto a las de $M u$ qtabis han salido de la pluma de 'Abd al-Wāhid y que, por tanto, toda obra que presente esas variantes ha de derivar indefectiblemente de la suya. Por lo tanto, esta rama del stemma queda establecida así:

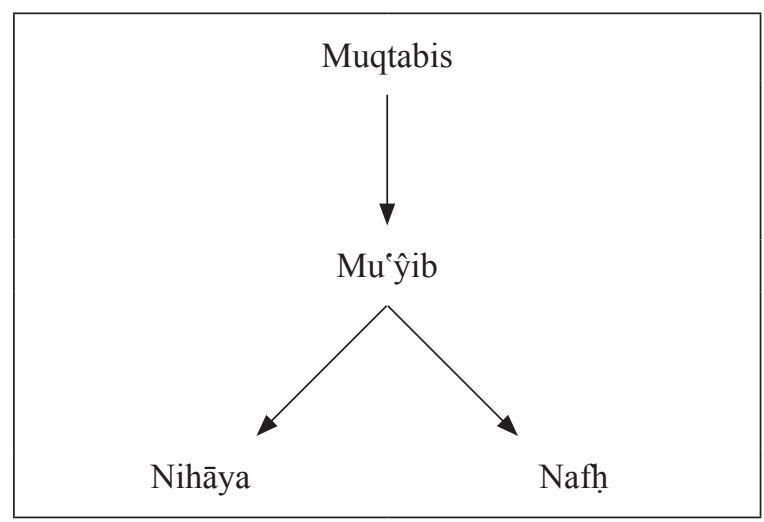

Quedaría únicamente ubicar en este cuadro el testimonio de Tartīb, el último de los representantes de la versión amplificada. En primer lugar hay que descartar la posibilidad de que Tartīb pueda ser fuente de $M u^{\prime} \hat{y} i b$, ya que éste atribuye el pasaje a Ibn Hayyān, dato que no podría haber hallado en Tartī $b$, que cita directamente a Ibn al-Qūtiyya. Pero que 'Iyāọ cite a Ibn al-Qūtiyya no implica que fuera realmente su fuente inmediata, pues no es nada infrecuente que los autores mencionen la fuente remota y omitan todo alusión a las intermedias. Por ello tan factible es que 'Iyāọ tuviera ante sí el original de Ibn al-Qūtiyya como que lo conociera a través de Muqtabis u otra fuente. A esclarecer esta cuestión, vital en el análisis que estamos realizando, dedicaremos el siguiente apartado. 


\section{Relaciones entre Muqtabis y Tartīb}

La confrontación de los pasajes sobre Țālūt contenidos en las obras de Ibn Hayyān y de 'Iyāḍ no aporta datos que clarifiquen su grado de parentesco textual. La mayoría del texto es idéntico en ambas fuentes $\mathrm{y}$, cuando se presenta alguna variante, casi siempre es debida a que Muqtabis ofrece alguna precisión que falta en Tartīb. La circunstancia contraria, es decir, que Tartīb sea más detallado que la crónica hayyyāní, se da en contadísimas ocasiones y ninguna de ellas se puede atribuir a que 'Iyād haya conservado lecturas presentes en el original de Ibn al-Qūtiyya. Por tanto resulta imposible la relación textual entre $\mathrm{Mu}$ qtabis y Tartīb en base al análisis de este pasaje y deberemos recurrir a otros testimonios para dar respuesta a esta cuestión.

Enumerábamos en su lugar las ventajas que presentaba el texto elegido para el estudio que emprendíamos, pero pasábamos por alto una característica que jugaba en contra nuestra: su carácter de texto unigénico, procedente de una única fuente. Este hecho facilita sin duda nuestra labor al evitar interferencias perturbadoras, pero, al mismo tiempo, priva al texto transmitido de esa personalidad que sólo puede ofrecer la mezcla, el mestizaje. Cuando manejamos un pasaje sin mezclas, nos es muy sencillo adscribirlo a su familia, hallar el grupo de textos con el que está emparentado, pero, una vez encuadrado en el conjunto, no es nada fácil precisar qué lugar ha de ocupar en esa estructura, dada la semejanza que todos los miembros de ese grupo presentan entre sí. Pero si, por el contrario, el texto a estudiar está compuesto por elementos de origen diverso, dispondremos de una serie de datos como la identidad de los componentes de la mezcla, la proporción en la que intervienen o el orden en el que se presentan que le otorgarán una personalidad definida, casi única.

Debemos, por tanto, encontrar otro texto de características similares al analizado (básicamente, que se conserve su fuente original y que Muqtabis y Tartīb lo reproduzcan) y que, además, utilice otras fuentes distintas de la estructural. Si Muqtabis y Tartīb sólo coinciden entre sí cuando citan a la fuente estructural, habrá que deducir que recurren a dicha fuente de forma independiente; pero si ambos presentan conjuntamente los inconfundibles rasgos que se forman al mezclar la fuente estructural con otras accesorias, la conclusión obvia habrá de ser que existe un subarquetipo en el que se habría producido esa mezcla de fuentes. Dicho subarquetipo podría ser tanto una 
fuente intermedia común a Muqtabis y Tartīb, como el propio Muqtabis, que sería la fuente de Tartīb.

No tenemos que irnos muy lejos dentro de Tartīb para hallar un texto de estas características. La biografía anterior a la de Ṭālūt, la del cadí Muhammad b. Bašīr al-Ma āfirī, es idónea y nos suministra información clara y definitiva para responder a las preguntas planteadas.

La larga biografía de Ibn Bašīr (TM, III, 327-339) que reproduce 'Iyāọ está basada primordialmente en la que le dedica Ibn Hārit alJušanī en sus Qudāt Qurțba (Historia de los jueces de Córdoba por Aljoxaní, ed. y trad. Ribera, J., Madrid, 1914, 51-67). Pero junto a las citas de esta fuente, perfectamente identificables ya que la obra de Ibn Hârit se nos ha conservado, hallamos una serie de párrafos de origen diverso. La escrupulosidad de 'Iyāḍ a la hora de mencionar sus fuentes nos permite conocer su origen. Los pasajes que no proceden de Qud̄àt son:

— Una interpolación del propio 'Tyāḍ (p. 335, líneas 9-12)

— Cita de al-Mabsūta de Yahyá b. Isḥāq (337.1-3) ${ }^{19}$, muy probablemente interpolado también por 'Iyāḍ.

— Tres breves párrafos atribuidos a Ibn al-Qūtiyya (327.11-13; 328.9$10 ; 329.2-6)$.

— Cita de Abū 'Abd al-Malik ibn `Abd al-Barr (331.4-10).

- Noticia sin atribución de fuente (332.13-15).

— Cita de Aslam b. 'Abd al-'Azīz (332.18-333.2).

- Otra noticia sin fuente explícita (335.14-16).

— Cita de Ibn Waḍdāḥ (338.1-339.6).

— Frase introducida por un «se cuenta» (339.7-9).

Tras confrontar estos pasajes con la biografía que Ibn Bašīr tiene en el Muqtabis se comprueba que todos ellos, excepto los dos primeros, que son añadidos del propio 'Iyād, se hallan reproducidos en la obra de Ibn Hayyān, que, ocioso es decirlo, los utiliza también para complementar las informaciones de su fuente básica, Ibn Ḥārit.

Si nos fijamos en las tres breves citas de Ibn al-Qūtiyya que Tartīb hace en este pasaje, comprobamos que presentan las mismas características que apreciábamos al estudiar la historia de Ṭâlūt: se hallan

19 Descendiente de Yahyà b. Yahyyà, autor de al-Kutub al-mabsūṭa fì jtilāf așhāa Mālik wa-aqwāli-hi (Marín, M. "Una familia de ulemas cordobeses: los Banū Abī '̄̄sà", Al-Qanțara, VI (1985), 291-320, 295-6).

Al-Qanțara XXXII 2, julio-diciembre 2011, pp. 533-557 ISSN 0211-3589 
también en el original de Ibn al-Qūtiyya y en Muqtabis ${ }^{20}$, pero la versión que da Tartīb está mucho más cercana a la de Ibn Ḥayyān que a la de Ibn al-Qūtiyya. La diferencia con el caso de Țâlūt es que, en esta ocasión, las citas de Ibn al-Qūtiyya en Muqtabis y Tartīb forman parte de un conjunto de interpolaciones con las que se complementa la fuente estructural del pasaje que, como ya se ha dicho, son los Qudāt Qurțba de Ibn Ḥārit. Es indudable que 'Iyāạ halló el texto resultante de la mezcla de Qudāt con otras obras secundarias (una de ellas, Ibn al-Qūtiyya) en una fuente indeterminada, que denominaremnos $M$, fuente que fue utilizada también por Ibn Hayyān (sin que podamos descartar que esa fuente fuera en realidad el mismo Muqtabis, que, en ese caso, pasaría a ser el texto en el que se basó Tartīb). Lo que es evidente es que 'Iyāọ no utilizó de forma directa a Ibn al-Qūṭiyya.

\section{Conclusiones}

El stemma que habíamos elaborado y que representaba gráficamente la estructura de relaciones textuales entre las distintas obras que recogen el relato de Țālūt había quedado incompleto. Habíamos logrado establecer la existencia de dos ramas nítidamente diferenciadas: la que surgía del texto reflejado en el manuscrito de París del Iftitāh de Ibn al-Qūtiyya (del que derivan Dayl y Siyar) y una segunda cuyo representante más antiguo es Muqtabis (fuente de Mugrib, Mu'ŷib, Nihāya y Nafh), a la que pertenece también, en una posición hasta ahora indefinida, Tartī $\bar{b}$. Tras lo analizado en los párrafos anteriores, sabemos ya que Tartīb no deriva directamente de Ibn al-Qūtiyya, sino que lo hace a través de una fuente intermedia, $M$ (que puede ser fuente también de Muqtabis o tratarse del mismo Muqtabis).

A la vista de todo esto, ¿podemos seguir dando credibilidad a la teoría de las dos redacciones de la «Historia» de Ibn al-Qūtiyya? Todo parece indicar que no. El principal argumento en el que se apoyaba esa teoría, la existencia de numerosas obras que reproducían la supuesta versión amplificada de Ibn al-Qūtiyya, queda invalidado ante la constatación de que todos esos testimonios se reducen a la hora de la verdad a uno solo, el de $M$, del que derivan todos los demás. Por otra parte, conocemos perfectamente, gracias al análisis de la biogra-

${ }^{20}$ Iftitāh, 45; Muqtabis, 201-202.

Al-Qanțara XXXII 2, julio-diciembre 2011, pp. 533-557 ISSN 0211-3589 
fía de Ibn Bašīr, el método historiográfico del compilador de $M$, fervoroso corrector estilístico y gramatical que no consiente que una cita de otro autor pase por su mano sin dejar su personal huella en ella.

En definitiva, las evidencias en favor de la existencia de una segunda versión de la «Historia» de Ibn al-Qūtiyyya se reducen al testimonio de una única fuente, fuente que, además, se caracteriza por no respetar nunca la literalidad del texto que copia. Frente a este endeble argumento, se alza el dato elocuente de la pervivencia de la que, según esa teoría, sería primera redacción, borrador de trabajo o apuntes de clase, que, a pesar de ello, sobreviviría en el único manuscrito que se conserva, elaborado cinco siglos después de la redacción de la obra, y serviría de fuente a obras tardías como al-Dayl wa-l-takmila de Ibn 'Abd al-Malik (s. XIII) y Siyar a 'lām al-nubalā' de al-Dahabī (s. XIV).

Es indudable que, con los datos que poseemos ahora, Ibn alQūtiyya escribió una sola versión de su Iftitāh al-Andalus, la reflejada en el texto del manuscrito de París, y que en ella se basaron diversos autores posteriores, uno de los cuales, el compilador de $M$, fue quien alteró sensiblemente la redacción, tal y como solía hacer con todo el material que utilizaba para elaborar su obra. Esa redacción amplificada conoció posteriormente un destacado éxito, debido sin duda a que era la recogida en el Muqtabis. Por tanto, cuando unificamos definitivamente las dos ramas del stemma que representa la transmisión de la historia de Țālūt, $M$, que, por motivos de claridad y comodidad seguimos identificando con Muqtabis, pasa a ser un subarquetipo:

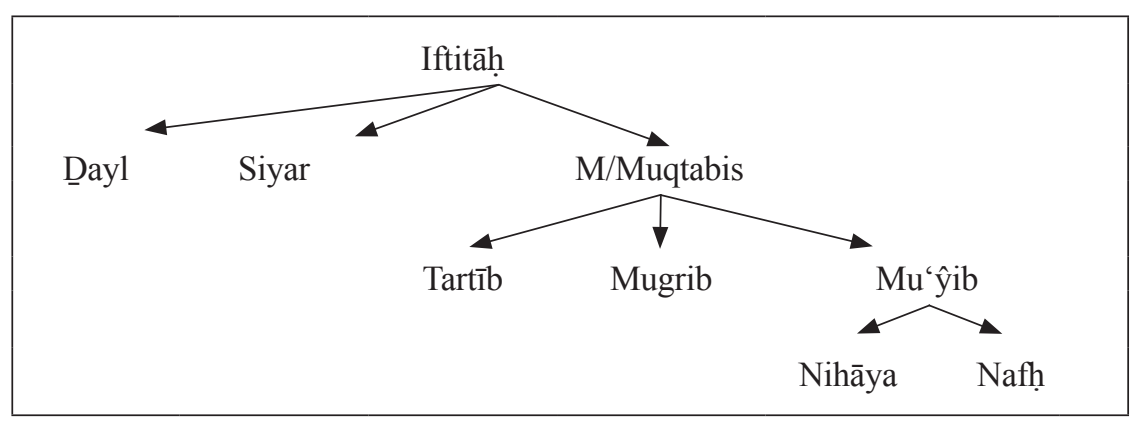

Recibido: $10 / 11 / 2010$ Aceptado: 30/05/2011 